\title{
Malignant fibrous histiocytoma: a case report
}

Received: 19 April 2008 / Accepted: 13 March 2009

(C) Association of Oral and Maxillofacial Surgeons of India 2009

\begin{abstract}
Malignant Fibrous Histiocytoma (MFH) is a controversial soft tissue malignancy whose pathogenesis continues to be redefined. It remains the most often used term for soft tissue sarcomas of late adult life. It has also been described to originate from the bone and rarely found in the mandible. Primary involvement of the mandible with MFH is an unusual presentation. A case of malignant fibrous histiocytoma, which posed a diagnostic difficulty, is presented here.
\end{abstract}

Keywords Malignant fibrous histiocytoma (MHF) · Mandible

\section{Introduction}

The term 'fibrohistiocytic tumor' was used by Enzinger and Weiss for a diverse group of tumors and tumor like lesions, which can be benign, malignant, or intermediate in behaviour. Malignant fibrous histiocytoma is the most common malignant mesenchymal tumor in adults [1]. Fibro histiocytic tumors predominantly affect the skin or skeletal muscles and are rare in the peri-oral tissue [2]. This highly malignant neoplasm has a variable morphology, which often causes difficulties in microscopic differential diagnosis. Knowledge of clinical presentation of $\mathrm{MFH}$ in the oral region is based on the summary of limited knowledge present in the literature.

\section{Report of a case}

A 16-years-old male patient, reported with the complaint of swelling, rapidly growing in nature, since last $1 \frac{1}{2}$ months which was present at the left angle of the mandible (Fig. 1).

The patient's history revealed pain in the lower left molar region 1 1/2 months ago for which he consulted the dentist. The swelling started enlarging rapidly in relation to the mandibular wisdom tooth and ramus of the mandible. The increase in size was associated with intense pain, and numbness of the lower lip. The mass was not fixed to the adjacent soft tissues. Regional lymphadenopathy was not evident. Medication in the form of analgesics and antibiotics was given. The patient was then referred to our centre.

Radiographic examination demonstrated a mixed radio opaque and radiolucent lesion which was poorly demarcated. Destruction of the bone was seen in the ramus perforating the cortical plate, extending to the angle and body of the mandible (Fig. 2).

Biopsy was done in the retromolar region which showed the presence of malignant fibrous histiocytoma.

\section{Management}

Hemi-mandibulectomy with disarticulation was performed with en bloc removal of the medial and lateral contiguous soft tissue (the block included submandibular salivary gland and lymph nodes). The plane of dissection was superficial to the periosteum outside the suspected anatomical boundary of the tumor [3] (Fig. 3). After resection of tumour reconstruction of the defect was done by angled reconstruction plate (Fig. 4). Primary closure of the defect was done (Fig. 5). Patient was under follow-up for a period of 18 months. There was a recurrence of the tumour after 36 months. CT scan of the patient revealed tumour spread to infratemporal fossa and base of the skull. There was no metastasis other than the head and neck region. Patient was kept on palliative therapy and passed away after 3 months.
Abhay Datarkar ${ }^{1} \bowtie \cdot$ Hazare $V^{2}$

${ }^{1}$ Associate Professor

Dept. of Oral and Maxillofacial Surgery

Sharad Pawar Dental College, Maharashtra

${ }^{2}$ Dean, Professor and Head

Dept. of Oral Pathology, Government

Dental College, Maharashtra

\section{Address for correspondence:}

\section{Abhay Datarkar}

Associate Professor

Dept. of Oral and Maxillofacial Surgery

Sharad Pawar Dental College

Sawangi (Meghe), Wardha

Maharashtra, India

Mobile: 0919822698145

E-mail: abhaydatarkar@yahoo.com

\section{Examination of the specimen}

Gross: The lesion was of the size $6 \mathrm{~cm} \mathrm{x} 7$ $\mathrm{cm} \times 8 \mathrm{~cm}$ without any pathologic fracture (Fig. 6).

Light microscope examination: Histologic sections of formalin-fixed paraffin embedded tissue were examined. The tumor infiltrated adjacent soft tissue and bone. Elongated cells resembling fibroblasts and rounded neoplastic cells were seen (Figs. 7 and 8). Fibrosis and hyalinization areas were seen.

\section{Discussion}

Malignant fibrous histiocytoma was first described by O'Brien and Stout in the year 1964. Ackerman's view as cited by Arturo Vargas [4], the term histiocytoma refers to the tumors in which most or all of the cells have appearance of histiocytes with few fibroblast like cells. Tumors having a conspicuous fibroblastic element in addition to the histiocytes are referred to as fibrous histiocytomas. The name of malignant fibrous histiocytoma is proposed for a variant of fibrous histiocytoma in which mono or multinucleated cells of bizarre malignant appearance are added to the histiocytic and fibroblastic background.

Malignant fibrous histiocytoma occurs more frequently in males than in female patients in a ratio of approximately 1.5:1 


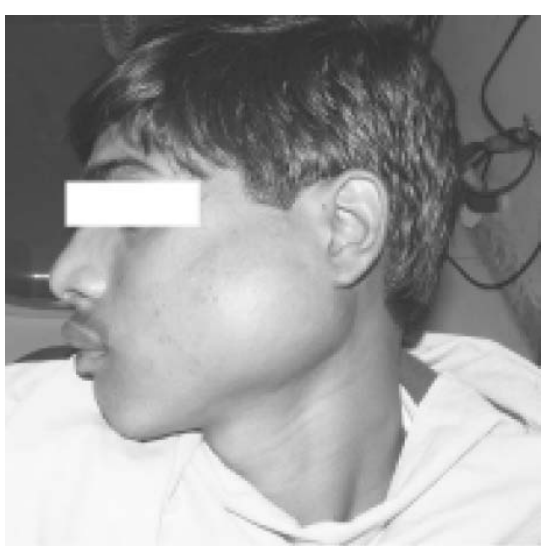

Fig. 1 Preoperative clinical presentation

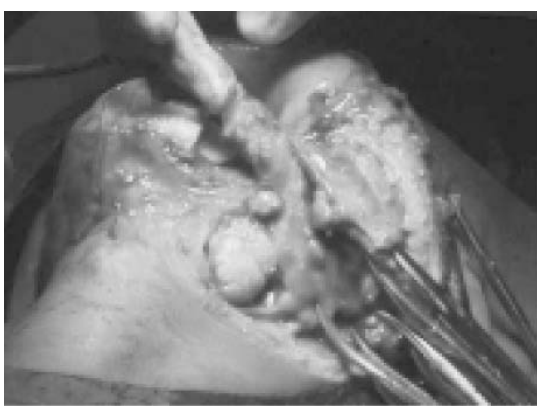

Fig. 3 Intraoperative view showing plane of dissection

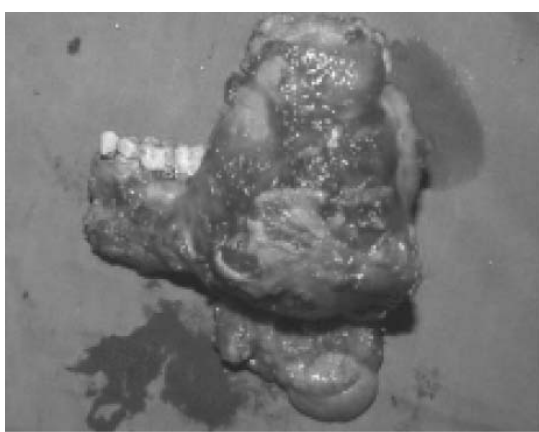

Fig. 6 Resected specimen

[5]. Most commonly affects the patients in the fifth decade of life, with median ages between 60 and 65 years. However patients of all ages are affected with roughly 590 cases occurring in teenages. Most malignant fibrous histiocytoma develop as painless enlarging masses that are usually present for less than a year, though $1 / 4$ of patients have some pain associated with the mass.

The tumor has a non specific gross appearance as either a nodular or multinodular, well circumscribed firm or fleshy mass. Depending upon their cellular composition they have a gray, white or yellowish cast, the last caused by high cellular fat contents. Myxoid area in the tumors have translucent or mucoid cut surfaces.

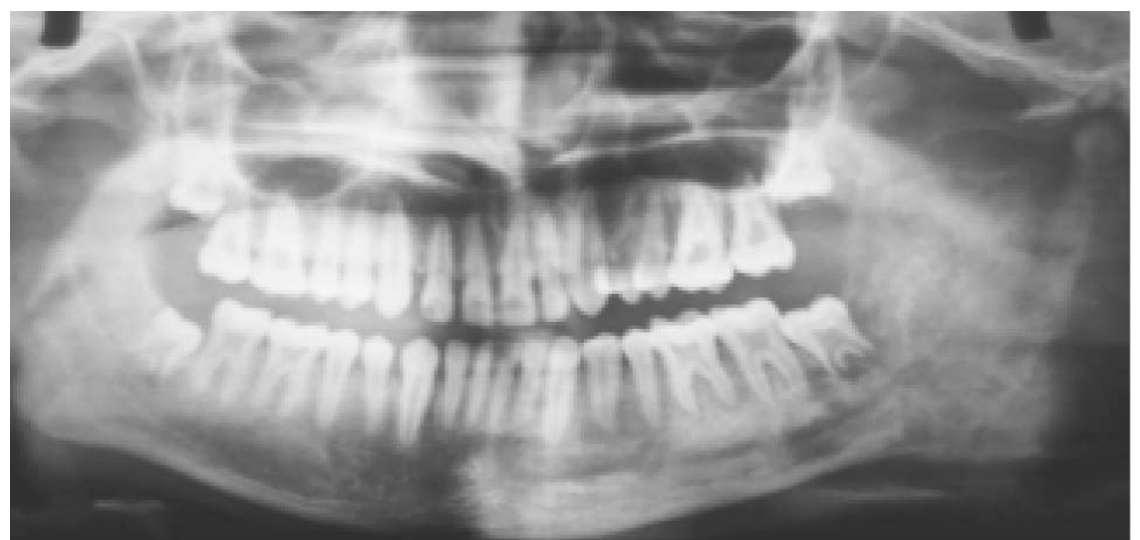

Fig. 2 Orthopantomogram

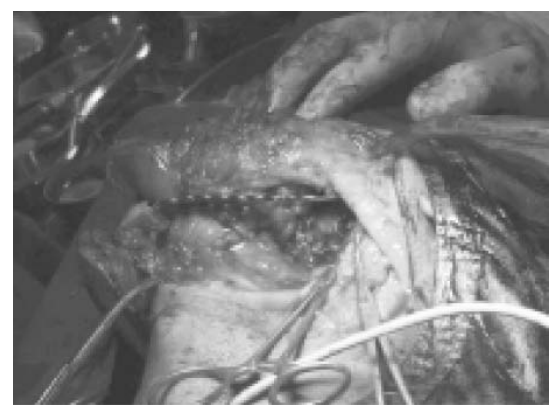

Fig. 4 Intraoperative view showing reconstruction

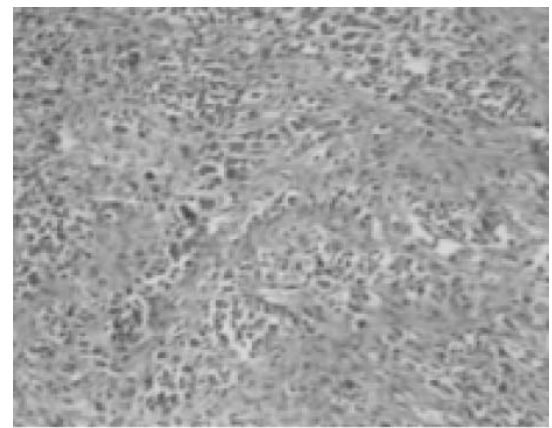

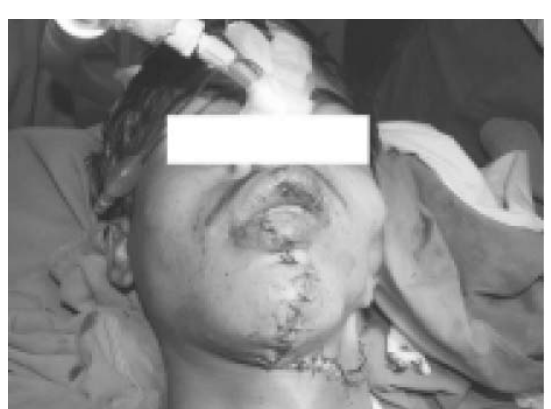

Fig. 5 After primary closure of the defect

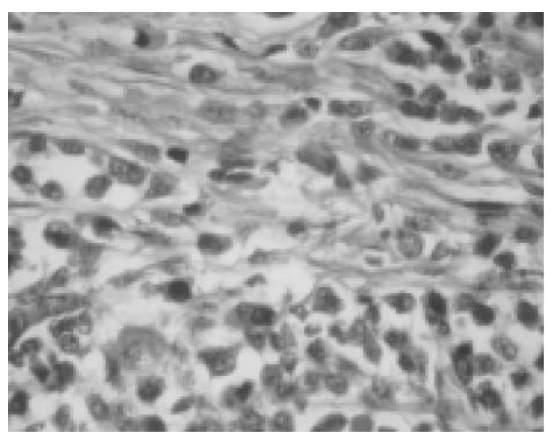

Fig. 7 and 8 Microscopic features showing chronic inflammatory cells, abundant granular cytoplasm and fibrosis

\section{Histogenesis}

The tumor contains both fibroblast like and histiocyte like cells in varying proportions with spindled and rounded cells and numerous large bizarre tumor giant cells. It was initially proposed that the tissue histiocyte was acting as a facultative fibroblast and that this explained the apparent bimodal cell population. The neoplastic histiocytes were reported to poses ultra structural attributes such as collagen production. Fibrosis may be minimal or quite extensive with broad hyalinized regions present. Ultra structural and tissue culture experiments demonstrated small numbers of undifferentiated mesenchymal cells and it is suggested that the tumor arises from these progenitor cells [6]. Now there is a general agreement that the progenitor cell of MFH is probably not a mononuclear phagocyte but rather an undefined mesenchymal cell [7].

The clinical stage of tumor which is defined by tumor growth, size and presence of distant metastasis is the most important prognostic factor. The anatomic site and depth of primary tumors may also be of prognostic value but this is controversial. Four variants showing differing clinical and histological features have been recognized: pleomorphic storiform, myxoid, giant cell, inflammatory. The inflammatory and to a lesser extent, the pleomorphic variants are more aggressive, metastasize early, and respond less favorably to surgery alone [8]. The case reported here was of myxoid type with pleomorphic variations. 
Approximately $40 \%$ to $50 \%$ malignant fibrous histiocytomas recur after excision, with radical excision, yielding lowest rate of recurrence. The principle sites of metastasis is the lungs, some variations are reported in the involvement of regional lymph nodes, with some authors reporting a relatively low incidence of $2 \%$ to $17 \%$.

\section{MFH and mandible}

Based on the small number of cases cited in the literature it is difficult to enumerate pathognomonic features suggestive of MFH in the mandible. The common presenting symptom is pain, rapidly enlarging mass, located in the posterior body or ramus, loosening of teeth, consistency elastic to firm [4,7-11]. There is absence of metastasis at the initial examination.

In the cases of MFH of the mandible previously published no special attention has been paid to the radiographic characteristics. Reported radiographic features are those of any aggressive osseous malignant lesion like poorly differentiated margins, cortical plate expansion or perforation, either unilocular or multilocular. These findings of MFH in the mandible are compatible with those of the lesions occurring in other bones [9]. Exact origin of the tumors involving both the bone and soft tissue bears no clinical significance in terms of tumor behavior and treatment planning [7].
Surgery, radiation therapy, and chemotherapy alone or in combination, have been employed in the treatment protocols for the cases in literature. The management of MFH of the mandible requires early radical surgery including removal of adjacent normal tissue with a minimum of $3 \mathrm{~cm}$ tumor margins. The efficacy of radiotherapy and chemotherapy for MFH is not yet established [12]. However there is no consistent relationship between the type and complexity of therapy and the survival rate. MFH shows early metastasis, hence early radical surgery and followup is indicated. In a review of treatment options for MFH, Besly et al. have suggested that the neoplasm is best treated surgically [6]. Radical neck dissection does not appear to be indicated unless there is clinical evidence of lymph node metastasis.

\section{References}

1. Enzinger FM, Weiss SW (1995) Soft tissue tumors, ed 3, C.V. Mosby, St. Louis

2. Roderick AC, William HB, Paul S, Andrew WB, John MW (1998) Lucas's Pathology of Tumors of the Oral Tissues, ed 5, Churchill Livingstone, London

3. Gold L (1991) Clinics of oral and maxillofacial surgery

4. Arturo V, Edgar E, Julio EG (1987) Primary malignant fibrous histiocytoma of the mandible. J Oral Maxillofacial Surg 45(7): 637-638

5. Kissane JM (1991) Anderson's pathology, Ed 9, vol 2, The C. V. Mosby Company, New Delhi

6. Besly W, Wiesenfeld D, Kleid S, Allan P, Poker I (1993) Malignant fibrous histiocytoma of the maxilla - a report of two cases. Br J Oral Maxillofac Surg 31(1): 45-48

7. Lin SK, How SW, Wang JT, Liu BY, Chiang CP (1994) Oral post - radiation malignant fibrous histiocytoma: A clinicopathological study. J Oral Pathology Med 23(7): 324-329

8. Block MS, Cade JE, Rodriguez FH Jr (1986) Malignant fibrous histiocytoma in the maxilla: review of literature and case report. J Oral Maxillofac Surg 44(5): 404-412

9. Anavi Y, Herman GE, Graybill S, MacIntosh RB (1989) Malignant fibrous histiocytoma of the mandible. Oral Surg Oral Med Oral Pathol 68(4): 436-443

10. Happonen RP, Ekfors T, Suonpaa J, Forssell K (1988) Malignant fibrous histiocytoma of the jaws: report of two cases. J Oral Maxillofac Surg 46(8): 690-693

11. Nuamah IK, Browne RM (1995) Malignant fibrous histiocytoma presenting as peri oral. Int $\mathbf{J}$ Oral Maxillofac Surg 24(2): 158-159

12. Senel FC, Bektas D, Caylan R, Onder E, Gunhan O (2006) Malignant Fibrous Histocytoma of mandible. Dentomaxillofac Radiol 35(2): 125-128 